\title{
Differences in American English, Spanish, and monkey perception of the say-stay trading relation
}

\author{
JOAN M. SINNOTT and TANYA A. SAPORITA \\ University of South Alabama, Mobile, Alabama
}

\begin{abstract}
An interesting phenomenon in human speech perception is the trading relation, in which two different acoustic cues both signal the same phonetic percept. The present study compared American English, Spanish, and monkey listeners in their perception of the trading relation between gap duration and $F 1$ transition onset frequency in a synthetic say-stay continuum. For all the subjects, increased gap duration caused perception to change from say to stay; however, subjects differed in the extent to which the $F 1$ cue traded with gap duration. For American English listeners, a change from a low to a high $F 1$ onset caused a phoneme boundary shift of $26 \mathrm{msec}$ toward shorter gap durations, indicating a strong trading relation. For Spanish listeners, the shift was significantly smaller at $13.7 \mathrm{msec}$, indicating a weaker trading relation. For monkeys, there was no shift at all, indicating no trading relation. These results provide evidence that the say-stay trading relation is dependent on perceptual learning from linguistic exposure.
\end{abstract}

There is currently much interest in determining the basis for trading relations in human speech perception. A trading relation is a phenomenon in which two different acoustic cues signal the same phonetic percept. Within limits, the cues trade with one another along a synthetic speech continuum - that is, the value of one cue may be increased while the value of the other is decreased, yet the phonetic percept remains the same for the listener. For example, one of the first trading relations to be studied in detail was that between voice onset time (VOT, a temporal cue) and $F 1$ onset frequency (a spectral cue) as perceived by American English (AE) listeners: As the $F 1$ onset frequency increases (decreases) in a synthetic VOT continuum, more voiceless (voiced) stimuli are perceived, thus shifting the phoneme boundary toward lower (higher) values of VOT (Summerfield \& Haggard, 1977).

What causes a trading relation? The most parsimonious explanation is that the effect is due to generalized psychoacoustic mechanisms that are innate and immutable in all normal listeners and, thus, independent of language learning (e.g., Kluender \& Lotto, 1994). A second possibility is that trading relations are due to perceptual learning from linguistic exposure, including articulatory processes (e.g., Best, 1995). These two types of mecha-

Portions of this research were based on a masters thesis by T.A.S. in the Department of Psychology. This research was supported by NIH Grant R01 DC00541 to J.M.S. and by the Sinnott Family Fund of the Fidelity Investments Charitable Gift Fund. We thank Kelly Mosteller and Trina Williamson for their help in testing monkeys. Correspondence concerning this article should be addressed to J. M. Sinnott, Comparative Hearing Laboratory, Department of Psychology, University of South Alabama, Mobile, AL 36688 (e-mail: jsinnott@jaguar1. usouthal.edu). nisms are not necessarily mutually exclusive, however, and it is likely that trading relations, as well as other aspects of speech perception, implicate both innate and learned mechanisms that interact to varying degrees (see, e.g., Pisoni, Lively, \& Logan, 1994).

There are several ways in which the relative contributions of psychoacoustic versus perceptual learning processes in speech perception could be evaluated. First, we can compare the perception of native and nonnative listeners. Differences would obviously support a perceptuallearning component, because there is no reason to expect psychoacoustic differences in sensitivity between native and nonnative listeners. Second, we can compare the perception of native listeners with animal listeners. This strategy, which has been used for over 20 years (e.g., Kuhl, 1986), stems from the assumption that animal listeners have basic psychoacoustic processes similar to those of humans but little, if any, linguistic exposure. If this assumption is correct, perceptual similarities between humans and animals in speech perception would support the idea of a common psychoacoustic component.

Several studies have examined how nonnative listeners, young children, and animals perceive English trading relations. An early study by Simon and Fourcin (1978) studied the VOT $/ F 1$ trading relation in the perception of stop voicing contrasts (Summerfield \& Haggard, 1977) for English and French children, with ages ranging from 2 to 14 years old. Some of the stimuli had a level $F 1$, and others had a rising $F 1$ transition with a low-frequency onset. The results showed that English children were more likely to call the stimuli with the rising $F 1$ transition voiced, whereas French children disregarded this cue. In addition, English children did not start to use the $F 1$ cue until about 5 years of age. Although the data show some ques- 
tionable results with regard to exact developmental trends, the authors maintained that perceptual learning by English children was involved in the development of the VOT $/ F 1$ trading relation.

However, recent animal data conflict with those of Simon and Fourcin (1978). Kluender and Lotto (1994) presented Japanese quail with synthetic VOT stimuli that contained either high or low $F 1$ transition onsets. The birds were trained to peck to the voiced (or voiceless) category and to withhold pecking for the opposite category. The birds' phoneme boundaries, as indicated by their pecking rates, were different for the high and low $F 1$ onset stimuli, with more voiced stimuli being reported in the latter condition. These results, in contrast to those of Simon and Fourcin, point to a psychoacoustic explanation for the VOT $F 1$ trading relation.

The trading relation in the AE liquid contrast $/ r /-/ 1 /$ has also been studied in cross-language and comparative experiments. The two important cues for liquids are the onset frequency of $F 3$ and the timing pattern of $F 1$ : Nor$\mathrm{mal} / \mathrm{r} /$ stimuli have a low $F 3$ onset frequency and a long $F 1$ transition, whereas /1/ stimuli have a high $F 3$ onset frequency and a short, delayed $F 1$ transition.

Using a cross-language design, Underbakke, Polka, Gottfried, and Strange (1988) presented $\mathrm{AE}$ and native Japanese listeners with a synthesized / $\mathrm{r} /-/ \mathbf{l} /$ continuum, in which a long (short) $F 1$ transition covaried appropriately with a low- (high-) frequency $F 3$ onset, and with two altered continua, which varied $F 3$ normally but had either a long or short $F 1$ transition. All the subjects first had to identify the end points of the normal $/ r /-/ 1 /$ continuum. When the altered continua were presented, the $\mathrm{AE}$ and the skilled Japanese listeners identified more $/ \mathbf{r} /$ (/1/) stimuli in the continuum with the long (short) $F 1$ transition, indicating a trading relation. Even the unskilled Japanese listeners, who were unable to reliably identify the endpoints of any continuum, showed a tendency for more stimuli to be identified as / $\mathbf{r} /$ when they contained the slow $F 1$ transition, indicating some sensitivity to the trading relation. To some extent, therefore, these data from the unskilled Japanese subjects suggest a psychoacoustic process.

Using a comparative design, Sinnott and Brown (1997) studied the $/ \mathrm{r} /-/ 1 /$ trading relation in AE listeners and Japanese monkeys, using stimuli patterned after those of Underbakke et al. (1988). The monkeys first learned to identify the end points of a normal $/ r /-/ 1 /$ continuum and showed phoneme boundaries similar to those of AE humans. In addition, when presented with the altered continua, the monkeys also showed shifting phoneme boundaries that were dependent on the duration of the $F 1$ transition, and their overall performance was identical to that of the AE listeners. Therefore, these monkey data also indicate a psychoacoustic process.

However, the results of both Underbakke et al. (1988) and Sinnott and Brown (1997) must be qualified in that the subjects of interest (i.e., the Japanese humans and the monkeys) were previously exposed to a normal $/ \mathbf{r} /-/ 1 /$ continuum in which the $F 1$ and $F 3$ cues covaried properly. Thus, the subjects could have learned to associate the two cues that trade with each other. Therefore, these data do not show that the $/ \mathrm{r} /-/ 1 /$ trading relation was perceived spontaneously (i.e., without previous exposure to appropriately covarying cues) by the Japanese humans and the monkeys. In contrast, the Japanese quail appeared to perceive the VOT/F1 trading relation spontaneously, since they were never previously exposed to the appropriately covarying cues (Kluender \& Lotto, 1994). Nevertheless, the comparative $/ \mathrm{r} /-/ 1 /$ data do indicate that, even if the trading relation was not perceived spontaneously, it could be learned by Japanese human and monkey listeners using basic psychoacoustic processes.

Another well-known $\mathrm{AE}$ trading relation is that between gap duration and $F 1$ transition onset frequency, which affects the perception of a voiceless stop $/ \mathbf{p} /$ or $/ \mathbf{t} /$ in a word-initial consonant cluster. Fitch, Halwes, Erickson, and Liberman (1980) first discovered this effect in a synthesized slit-split continuum that contained variable gap durations and either a low or a high $F 1$ onset. They found that a low (high) $F 1$ onset caused more split (slit) perceptions, shifting the phoneme boundary to shorter (longer) gap durations. Best, Morrongiello, and Robson (1981) later replicated this effect with a say-stay continuum. Specifically, they found that a relatively low $(230 \mathrm{~Hz})$ $F 1$ onset resulted in a say-stay boundary at a $32-\mathrm{msec}$ gap duration, while a higher onset frequency $(430 \mathrm{~Hz})$ resulted in a $57-\mathrm{msec}$ boundary. Thus a frequency difference of $200 \mathrm{~Hz}$ was perceptually equivalent to a gap duration of $25 \mathrm{msec}$.

Morrongiello, Robson, Best, and Clifton (1984) and Nittrouer (1992) studied the say-stay trading relation in young $\mathrm{AE}$ children and found phoneme boundary shifts about one-half the size of adults', so that a frequency difference of $200 \mathrm{~Hz}$ in $F 1$ onset shifted the phoneme boundary only about $10-12 \mathrm{msec}$. However, differences in adult-child perception cannot be used by themselves to evaluate the relative contribution of perceptual learning, because these differences could also be due to psychoacoustically based maturation effects.

To summarize, the existing cross-language/comparative/ developmental data concerning trading relations are very inconclusive with regard to the underlying mechanisms. Some data conflict (Kluender \& Lotto, 1994; Simon \& Fourcin, 1978); other data are confounded, because the subjects of interest could have learned the trading relation through previous exposure to normal covarying cues (Sinnott \& Brown, 1997; Underbakke et al., 1988); and the developmental data cannot differentiate between maturational psychoacoustic and perceptual-learning differences in children and adults (Morrongiello et al., 1984; Nittrouer, 1992).

The goal of the present study was to further explore the say-stay trading relation by testing two new study populations: adult humans who are nonnative English listeners and monkeys. We chose to use say-stay because two very clear developmental studies exist showing that this 
trading relation is incompletely developed in $\mathrm{AE}$ children (Morrongiello et al., 1984; Nittrouer, 1992). It is a good candidate, therefore, by which to show the involvement of perceptual learning.

We chose to use Spanish listeners as our nonnative human controls, primarily because the Spanish language does not normally use consonant clusters in word-initial position, except in rare cases of words borrowed from other languages (Merriam-Webster's Spanish-English Dictionary, 1998). Thus, Spanish does not have native contrasts such as say-stay. In fact, Spanish uses an [e]epenthesis rule (e.g., standard $\rightarrow$ estandar) to syllabify $s$ clusters in initial position (Lleo \& Prinz, 1996). It is possible, therefore, that the phonological constraint in Spanish listeners against initial st clusters may cause their perceptual processing of AE word-initial st clusters to be different from that of native AE listeners.

Human and monkey subjects in the present study were tested, for the most part, with identical stimuli and procedures, and no subjects were previously exposed to the appropriately covarying cues of gap duration and $F 1$ onset in normal full-cue say-stay stimuli. Thus, our study tested for spontaneous, rather than for learned, perception of the trading relation.

We therefore propose the following with regard to the say-stay trading relation: (1) Perceptual differences in $\mathrm{AE}$ and Spanish listeners would support a perceptuallearning hypothesis, and (2) perceptual similarities in all the humans and monkeys would support a psychoacoustic hypothesis.

Other outcomes are also possible, but they would be difficult to interpret; for example, suppose the $\mathrm{AE}$ and Spanish human listeners performed similarly in exhibiting the trading relation but were different from the monkeys, who did not? This could imply that (1) Spanish listeners can learn to use the $\mathrm{AE} F 1$ onset cue during their limited exposure to English, but monkeys cannot, (2) Spanish listeners also use an $F 1$ onset cue to differentiate $s-s t$ contrasts (since Spanish does use word-medial st clusters), or (3) human psychoacoustic processes, specifically regarding the way gap duration interacts with $F 1$ onset to form the trading relation, are different from those of monkeys.

\section{METHOD}

\section{Subjects}

The AE subjects were 9 monolingual adults whose native language was English (see Table 1). Two of the AE subjects were the authors; the others were students or technicians working in the Comparative Hearing Lab. The Spanish subjects were 9 adults whose native language was Spanish (see Table 2). Eight Spanish subjects were recruited from the USA Center for Learning English as a Second Language; their first exposure to English had occurred as adults. All had strong Spanish accents; 1 (L.U.I.) required a translator to participate in the study. The 9th subject (R.E.B.) had learned English at the age of 7, and spoke with a very slight accent. All the human subjects, except the authors, were naive as to the purpose of the study and were paid $\$ 5$ for each 15 -min experimental session. None reported any speech or hearing difficulties.
The monkey subjects were 2 Japanese macaques, Dart and Harry (Macaca fuscata), each about 13 years old. Both had normal hearing, as assessed annually by hearing tests in the laboratory. Both had previously participated in several speech perception experiments involving stop-glide, liquid, and place-of-articulation contrasts. In particular, both had previously exhibited the $\mathrm{AE} / \mathrm{r} /-/ 1 /$ trading relation after exposure to normal $/ \mathrm{r} /-/ 1 /$ continua with covarying cues (Sinnott \& Brown, 1997). In addition, both monkeys were constantly exposed to conversational English when humans spoke to them around the laboratory.

\section{Apparatus}

Testing took place within a double-walled, IAC booth $(1.98 \times 1.82$ $\times 1.52 \mathrm{~m}$ ) padded with sound-insulating acoustic foam (Sonex Acoustical Products). The stimulus system included a Tucker-Davis Technologies (TDT) 16-bit digital-analog converter, an anti-aliasing filter set at $8 \mathrm{kHz}$ (TDT), an attenuator (TDT), an amplifier (NAD $3240 \mathrm{PE}$ ), and a loudspeaker (Polk 10). The speaker was located inside the booth about $84 \mathrm{~cm}$ from the head of a subject. The subjects responded by contacting a three-position metal lever and moving it to the left or the right in response to a stimulus. A cuelight was mounted above the lever. During testing, the humans sat in an ordinary chair, with the lever apparatus mounted on a stand before them. The monkeys sat in a custom-made primate chair, and the lever apparatus was screwed into the front of the chair. A copper cup placed next to the lever was connected to an automatic feeder (Gerbrands) that dispensed 190-mg banana- or bacon-flavored food pellets (Noyes) to the monkeys as rewards. Stimulus delivery, experimental contingencies, and response recording were controlled by a Compaq computer.

\section{Stimuli}

Say-stay stimuli similar to those used in Best et al. (1981) were synthesized by using the Computerized Speech Research Environment (AVAAZ Innovations, ON, Canada). Two continua were synthesized: Both consisted of eight stimuli that varied in gap duration but differed in the onset frequency of the $F 1$ transition at the start of the vowel. The stimuli consisted of four parts.

The initial / $/$ / frication noise. The noise was $100 \mathrm{msec}$ in duration, with a 10 -msec rise time. Amplitude of voicing (AV) was turned off, and amplitude of frication (AF) was set to $50 \mathrm{~dB} . A 1$ through $A 4$ were turned off, $F 5$ and $F 6$ were set to default values of 3750 and $4900 \mathrm{~Hz}$, respectively, with $A 5$ and $A 6$ both set to $45 \mathrm{~dB}$.

The variable silent gap duration. Gaps were $0,10,20,30,40$, 60,80 , and $100 \mathrm{msec}$ for humans and $0,20,40,60,80,120,160$, and $200 \mathrm{msec}$ for monkeys, because 1 monkey (Harry) had difficulty learning to identify stimuli with 0 - and $100-\mathrm{msec}$ gaps. During the gap, AV and AF were turned off.

The $F 1$ transition. The transition into the vowel was $50 \mathrm{msec}$ long. AV was set to $55 \mathrm{~dB}$. F0 started at $100 \mathrm{~Hz}$ and decreased to $80 \mathrm{~Hz}$ over the remainder of the transition and vowel. For the low $F 1$ onset continuum, $F 1$ started at $200 \mathrm{~Hz}$ and rose to $530 \mathrm{~Hz}$; for the high $F 1$ onset continuum, $F 1$ started at $500 \mathrm{~Hz}$ and rose to $530 \mathrm{~Hz}$. The other formant transitions were identical for the two continua: $F 2$ rose from 1800 to $1840 \mathrm{~Hz} ; F 3$ decreased from 3000 to $2480 \mathrm{~Hz}$. $F 4$ through $F 6$ were flat. $A 1$ through $A 6$ were set to 47 , $43,43,20,20$, and $20 \mathrm{~dB}$, respectively.

The diphthongized vowel. The vowel was $250 \mathrm{msec}$ long. AV remained at $55 \mathrm{~dB}$, falling to $0 \mathrm{~dB}$ over the last $5 \mathrm{msec} . F 1$ remained at $530 \mathrm{~Hz}$ for $150 \mathrm{msec}$, then fell to $270 \mathrm{~Hz}$ over the last $100 \mathrm{msec}$. $F 2$ remained at $1840 \mathrm{~Hz}$ for $150 \mathrm{msec}$, then rose to $2290 \mathrm{~Hz}$ over the last $100 \mathrm{msec} . F 3$ remained at $2480 \mathrm{~Hz}$ for $150 \mathrm{msec}$, then rose to $3000 \mathrm{~Hz}$ over the last $100 \mathrm{msec} . F 4$ through $F 6$ and $A 1$ through $A 6$ were set as in the transition period.

\section{Procedure}

A go-left/go-right identification procedure (Owren, 1990) was used as follows. At the beginning of a trial, the flashing cuelight 

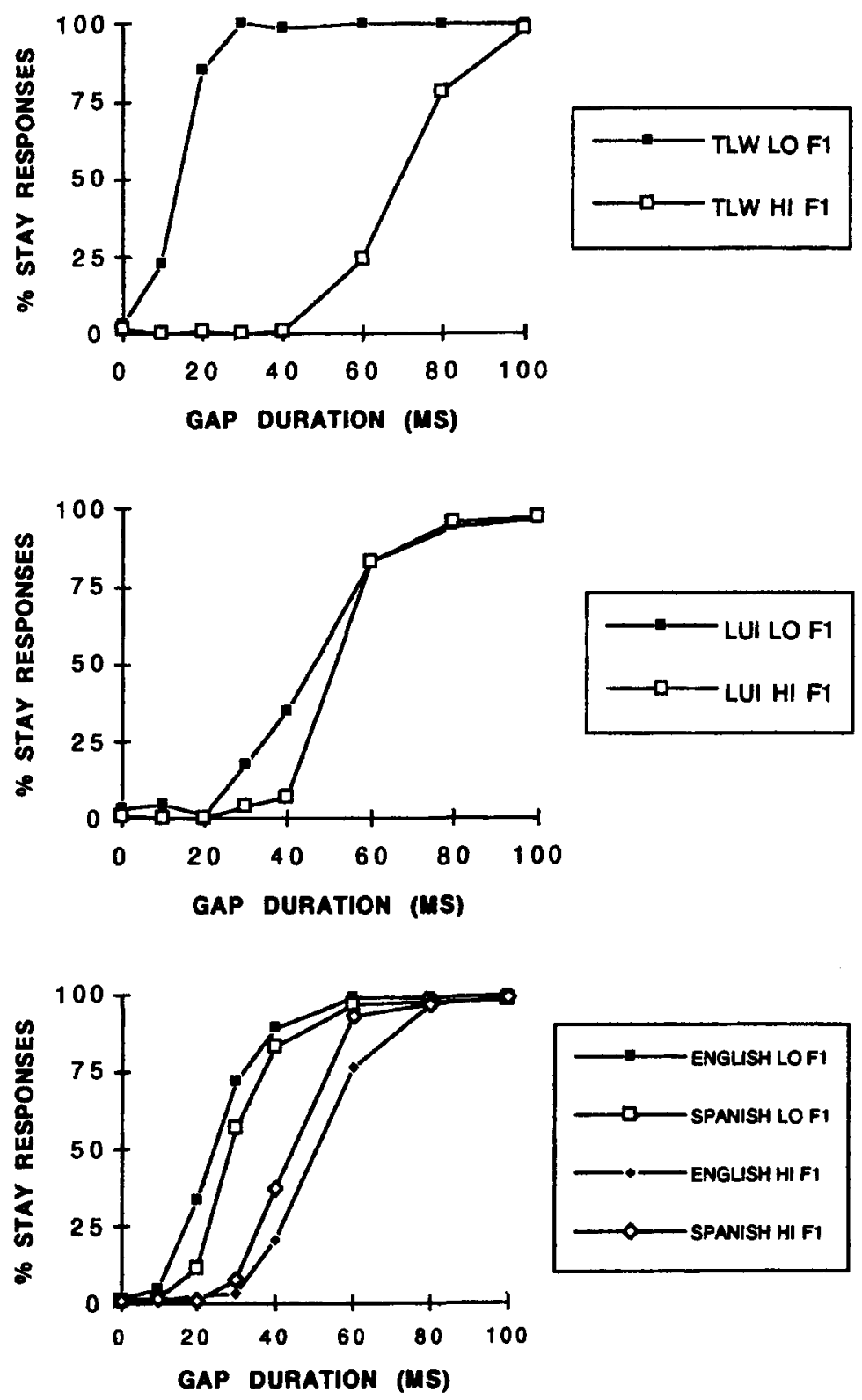

Figure 1. Top: identification functions for American English subject T.L.W., showing a boundary shift of 56 msec. Middle: identification functions for Spanish subject L.U.I., showing a boundary shift of $5 \mathrm{msec}$. Bottom: averaged identification functions for all the American English and all the Spanish subjects. The subjects were tested with a gap range of $0-100$ msec.

signaled the subject to contact the lever, at which time the cuelight stopped flashing and remained on. After a variable (1-2 sec) hold, either Stimulus I (say; 0-msec gap) or Stimulus 8 (stay; 100-msec gap for humans, 200-msec gap for monkeys) from the continuum was randomly presented and continuously repeated until a response was made. A left response to say or a right response to stay resulted in a reward (feeder click for humans, food pellet for monkeys). If a subject released the lever at any time or pushed the lever in the wrong direction, an 8-sec time-out resulted, during which the light was turned off and further trials could not be initiated. The stimuli were presented at $60 \mathrm{~dB}$ SPL (A), which is approximately a $50-\mathrm{dB}$ sensation level for humans and monkeys in our test booth. During all training and testing, continua were alternated daily between the low $F 1$ onset and the high $F 1$ onset continua.

The human subjects were given a short description of the apparatus and then verbally instructed to work as follows: "During the experiment you will hear synthetic stimuli that sound like say and stay. You should move the lever left for say and right for stay. Some stimuli may sound ambiguous, but you must make a response in any case. If you make the wrong response, you will receive an 8-sec 
Table 1

Individual American English (AE) Subjects' Sex, Age, and Phoneme Boundaries (in Milliseconds) for the Low and High $F 1$ Onset Say-Stay Continua and the Amount of Phoneme Boundary Shift (in Milliseconds)

\begin{tabular}{lccccc}
\hline Subject & Sex & Age & Low $F 1$ & High $F 1$ & Shift \\
\hline A.D.G. & F & 21 & 23 & 36 & 13 \\
C.D.W. & M & 22 & 16 & 46 & 30 \\
J.M.S. & F & 50 & 30 & 52 & 22 \\
K.I.T. & F & 35 & 32 & 48 & 16 \\
K.W.M. & M & 31 & 22 & 50 & 28 \\
S.A.R. & F & 39 & 38 & 62 & 24 \\
T.A.S. & F & 23 & 24 & 51 & 27 \\
T.L.S. & F & 25 & 30 & 48 & 18 \\
T.L.W. & F & 23 & 14 & 70 & 56 \\
Mean & & & 25.4 & 51.6 & 26.0 \\
SD & & & 7.76 & 9.68 & 12.6 \\
\hline
\end{tabular}

Table 2

Individual Spanish Subjects' Sex, Age, Years of English, Native Country, and Phoneme Boundaries (in Milliseconds) for the Low and High F1 Onset Say-Stay Continua and the Amount of Phoneme Boundary Shift (in Milliseconds)

\begin{tabular}{lccclccc}
\hline Subject & Sex & Age & $\begin{array}{c}\text { Years of } \\
\text { English }\end{array}$ & Country & Low $F 1$ & High $F 1$ & Shift \\
\hline G.R.E. & M & 29 & $<1$ & Mexico & 25 & 35 & 10 \\
J.U.A. & M & 29 & 4 & Columbia & 42 & 51 & 9 \\
L.U.I. & F & 26 & $<1$ & Venezuela & 46 & 51 & 5 \\
M.A.L. & F & 22 & 2 & Guatemala & 24 & 50 & 26 \\
M.A.R. & F & 35 & 3 & Columbia & 25 & 35 & 10 \\
M.A.T. & F & 40 & $<1$ & Spain & 33 & 48 & 15 \\
M.O.N. & F & 36 & 5 & Peru & 24 & 48 & 24 \\
M.V.C. & F & 17 & $<1$ & Costa Rica & 32 & 45 & 13 \\
R.E.B. & F & 20 & 13 & Panama & 28 & 39 & 11 \\
Mean & & & & & 31.0 & 44.7 & 13.7 \\
SD & & & & & 8.14 & 6.61 & 7.00 \\
\hline
\end{tabular}

time-out. Please respond as correctly as possible and avoid timeouts." All the human subjects identified the end point stimuli of both continua at $\geq 90 \%$ correct in the first training session.

Monkeys were "instructed" to work as follows. Initially the left side stimulus say was attenuated by $10 \mathrm{~dB}$ relative to the right side stimulus stay. Both monkeys easily learned to perform this task, and the difference was gradually reduced over training sessions until Stimuli 1 and 8 were both presented at equal intensity. Monkeys required about 1 month of training to differentiate the stimuli at $\geq 90 \%$ correct at equal intensity.

When Stimuli 1 and 8 were reliably identified at $\geq 90 \%$ correct, the subjects began generalization testing, in which a portion of the stimuli were the Training Stimuli 1 or 8 , and the rest were the Test Stimuli $2-7$, consisting of variable gap durations. Humans were tested with $50 \%$ training and $50 \%$ generalization stimuli; monkeys were tested with $75 \%$ training and only $25 \%$ generalization stimuli, in order to ensure that their responses to the training stimuli would remain at $\geq 85 \%$. During testing, Stimuli 1 and 8 still required a left or a right response, respectively, for a reward, but the Test Stimuli 2-7 were rewarded for any response, left or right.

During generalization testing, all the subjects were required to maintain a level of $\geq 85 \%$ correct to the Training Stimuli 1 and 8 , to ensure that they were operating under a reliable degree of stimulus control. A psychometric function was obtained for each subject on each continuum by plotting the percentage of stay responses as a function of gap duration in milliseconds, averaged over all the test sessions. The phoneme boundary was considered to be the gap du- ration at which a subject responded with $50 \%$ say and $50 \%$ stay identifications. The human subjects completed 10 sessions on each continuum (totaling about 80 responses per test stimulus), whereas the monkeys completed 20 sessions (totaling about 240 responses per test stimulus).

The first part of the experiment compared the $9 \mathrm{AE}$ and the 9 Spanish human subjects, using a gap range of $0-100 \mathrm{msec}$. The second part of the experiment retested $4 \mathrm{AE}$ subjects from the first part, to compare them directly with the 2 monkeys, using a gap range of $0-200 \mathrm{msec}$.

\section{RESULTS}

\section{Comparison Between American English and Spanish Subjects}

For all the subjects, increased gap duration caused perception to change from say to stay; however, the $\mathrm{AE}$ and the Spanish listeners differed in their use of the $F 1$ onset cue in a trading relation with gap duration. Examples of some individual generalization functions for the high and low $F 1$ onset continua are shown in Figure 1. Large shifts in the phoneme boundary as a function of $F 1$ onset indicate strong trading relations; small shifts indicate weak ones.

The AE subject T.L.W. (top panel) showed the strongest trading relation ( $56 \mathrm{msec}$ ) of any subject, whereas the Spanish subject L.U.I. (middle panel) showed the weakest $(5 \mathrm{msec})$. The averaged functions for the AE and the Spanish subjects are shown in the bottom panel. Tables 1 and 2 show the say-stay phoneme boundaries for all individual human subjects in the low versus high $F 1$ onset continua. For the AE listeners (Table 1), a change from a low to a high $F 1$ onset caused boundary shifts of $13-56 \mathrm{msec}$ $($ mean $=26 \mathrm{msec})$; for the Spanish listeners $($ Table 2$)$, the shifts ranged from 5 to $26 \mathrm{msec}$ (mean $=13.7 \mathrm{msec}$ ).

A two-factor analysis of variance (ANOVA), with repeated measures on the $F 1$ onset variable, indicated that the overall main effect of language (AE vs. Spanish) on the boundaries was not significant $[F(1,16)=.067, p=$ .80]. The main effect of $F 1$ onset (high vs. low) on the boundaries was highly significant $[F(1,16)=71.290$, $p<.001]$. Most important, the interaction between language and $F 1$ was also significant $[F(1,16)=7.056, p=$ $.017]$, indicating that the boundary shifts were significantly larger for the AE listeners than for the Spanish listeners.

The slopes of the human functions were also compared, using the procedure of Kuhl and Miller (1978). The difference in milliseconds was measured between the $25 \%$ and the $75 \%$ stay identification levels for each subject on both the low and the high $F 1$ continua. The average boundary width was $13.0 \mathrm{msec}$ across all the subjects, and an ANOVA revealed no effect of language ( $p=.92)$, no effect of $F 1(p=.35)$, and no interaction $(p=.15)$.

\section{Comparison Between American English Human and Monkey Subjects}

For both humans and monkeys, increased gap duration caused perception to change from say to stay; however, the monkeys did not use the $F 1$ onset cue at all in a trading relation with gap duration. For AE humans, a change 

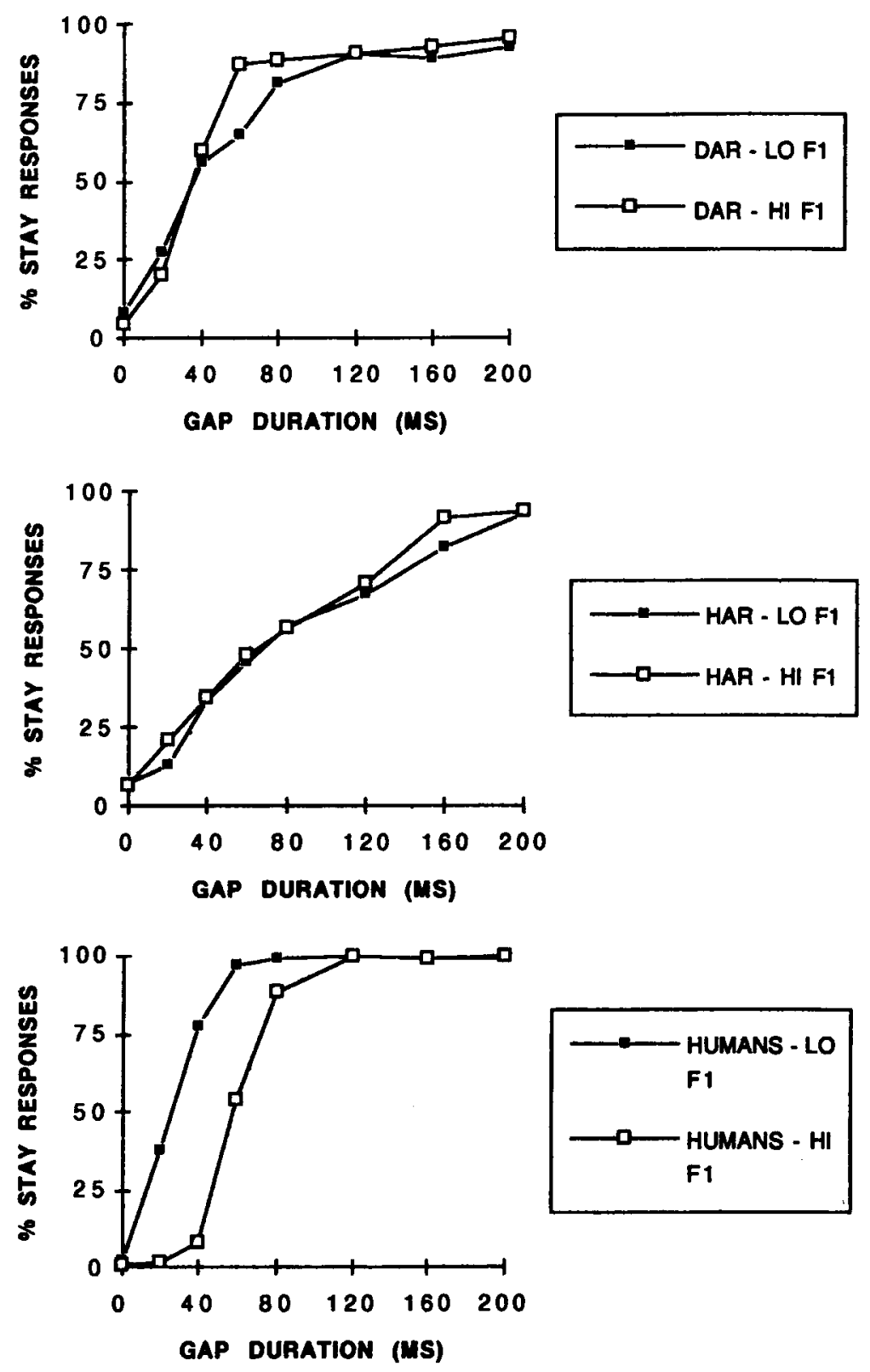

Figure 2. Top: identification functions for monkey Dart, showing no boundary shift. Middle: identification functions for monkey Harry, showing no boundary shift. Bottom: averaged identification functions for 4 American English humans. The subjects were tested with a gap range of $0-200$ msec.

from a low to a high $F 1$ onset caused boundary shifts of 23-57 msec (mean $=32.5$ ); for monkeys, there were no shifts at all. Examples of psychometric functions for both the high and the low $F 1$ onset continua, plotting the percent of stay responses as a function of gap duration from 0 to 200 msec, are shown in Figure 2. The 2 monkeys are shown in the top and middle panels; the averaged function for the 4 humans is shown in the bottom panel. Table 3 lists the individual say-stay phoneme boundaries.

Note that monkey Harry (Figure 2) showed much broader identification functions than monkey Dart or the other human subjects. Broader functions in animals are a common occurrence in comparative studies and are usually passed off as attentional differences between animals and humans (e.g., Kuhl \& Miller, 1978). However, since Harry's boundaries were similar to those of Dart, we did not explore this effect any further with Harry.

\section{DISCUSSION}

\section{Comparison With Other Studies} of the Say-Stay Trading Relation

The present results can be summarized as follows: $\mathrm{Na}$ tive adult $\mathrm{AE}$ listeners exhibited the strongest trading re- 
Table 3

Individual American English (AE) Human and Monkey Phoneme Boundaries (in Milliseconds) for the Low and High $F 1$ Onset Say Stay Continua and the Amount of Phoneme Boundary Shift (in Milliseconds)

\begin{tabular}{cllc}
\hline Subject & Low $F 1$ & High $F \mathbf{1}$ & Shift \\
\hline AE Humans & & & \\
J.M.S. & 48 & 72 & 24 \\
K.W.M. & 25 & 48 & 23 \\
T.A.S. & 27 & 53 & 26 \\
T.L.W. & 10 & 67 & 57 \\
Mean & 27.5 & 60.0 & 32.5 \\
SD & 15.6 & 11.3 & 16.4 \\
Monkeys & & & \\
Dart & 35 & 35 & 0 \\
Harry & 67 & 65 & -2 \\
Mean & 51.0 & 50.0 & -1.0 \\
SD & 22.6 & 21.2 & 1.4 \\
\hline
\end{tabular}

\begin{tabular}{|c|c|c|c|c|c|c|}
\hline Study & $\begin{array}{c}\text { AE } \\
\text { Adults }\end{array}$ & $\begin{array}{c}\text { Spanish } \\
\text { Adults }\end{array}$ & $\begin{array}{c}\mathrm{AE} \\
7 \text { years } \\
\end{array}$ & $\begin{array}{c}\mathrm{AE} \\
5 \text { years } \\
\end{array}$ & Monkeys & Range \\
\hline BMR1 & 25 & & & & & 136 \\
\hline BMR2 & 19 & & & & & 96 \\
\hline MRBC & & & & 11 & & 104 \\
\hline $\mathrm{N}$ & 18 & & 15 & 8 & & 55 \\
\hline Present study & 26 & 14 & & & & 100 \\
\hline Present study & 32 & & & & -1 & 200 \\
\hline
\end{tabular}

Note-BMR1, Best, Morrongiello, and Robson (1981, Experiment 1); BMR2, Best, Morrongiello, and Robson (1981, Experiment 2); MRBC, Morrongiello, Robson, Best, and Clifton (1984); N, Nittrouer (1992). Range, range of gap durations (in milliseconds) in the stimulus continua. AE, American English.

lations ( $26 \mathrm{msec}$ ), native adult Spanish listeners with less exposure to English exhibited significantly weaker trading relations (14 $\mathrm{msec})$, and monkeys exhibited no trading relations.

Table 4 summarizes all available data for the say-stay trading relation. The present results for adult AE listeners are comparable with those from previous studies. It is clear that adult $\mathrm{AE}$ listeners exhibit the strongest trading relations of all the populations tested so far (18-32 $\mathrm{msec}$, depending on the particular study and the stimulus range used). Adult Spanish listeners, for the most part unskilled in English, have smaller shifts, averaging $14 \mathrm{msec}$, which are within the range exhibited by $\mathrm{AE}$ children in the 5to-7-year-old range $(8-15 \mathrm{msec})$.

Of particular interest are the data of Nittrouer (1992). Note that she used a truncated range of gap duration up to $55 \mathrm{msec}$; thus, her stimuli are not directly comparable with those of the other studies. But she found a very interesting developmental effect in that the trading relations of the 7-year-old children $(15 \mathrm{msec})$ were actually closer to her adult values $(18 \mathrm{msec})$ than they were to those of her 5-year-old children $(8 \mathrm{msec})$. These data suggest that this trading relation may not reach the adult value until about age 7 and that, at age 5, it is only about one half the size of the adult value. Since the present data in- dicate that the Spanish listeners' trading relation was approximately one half the size of the AE listeners', it may be that native Spanish listeners learning English pass through a perceptual developmental stage roughly similar to that of 5-year-old AE children.

However, the exact relationship between degree of English exposure and size of the trading relation was difficult to pinpoint at the individual level. For example, our most "English-sophisticated" Spanish subject, R.E.B., with 13 years of English exposure, exhibited a trading relation of only $11 \mathrm{msec}$, which was smaller than that of any AE subject. But M.A.L., with only 2 years of English exposure, had one of $26 \mathrm{msec}$, comparable with the $\mathrm{AE}$ average.

\section{Perceptual Learning Versus Psychoacoustics in the Saystay Trading Relation}

In the present study, the AE listeners perceived a much stronger trading relation than did the Spanish listeners. Since there is no reason to hypothesize any psychoacoustic differences between $\mathrm{AE}$ and Spanish listeners, we assume that the important factor here was the degree of exposure to English. More linguistic exposure to English apparently resulted in a greater shift of the say-stay phoneme boundary when the $F 1$ onset frequency was changed. This result supports a perceptual learning component, at least for the strong say-stay trading relation of AE listeners.

Where, however, do the weak say-stay trading relations of the Spanish adults and the AE children come from? Are these psychoacoustically based, or has learning affected them to some extent, albeit not as extensively as in the case of the AE adults? Our data from monkeys provide a tentative answer to this question: With presumably general psychoacoustic capacities, they did not exhibit the trading relation. So the present data from native $\mathrm{AE}$, native Spanish, and monkey listeners, taken together, suggest that this trading relation is based totally on perceptual learning and that psychoacoustic capacities, at least as they are represented in other primate species, contribute little, if anything. 1

An obvious question is suggested by the data from the monkeys. Could monkeys be trained to perceive the saystay trading relation in a manner similar to native $\mathrm{AE}$ adults by explicitly exposing them to the two cues of gap duration and $F 1$ onset covarying appropriately? For example, suppose the monkey learns to go left to a short gap with a high $F 1$ onset, associating both cues as components of say, and to go right to a long gap with a low $F 1$ onset, associating both cues as components of stay. Would subsequent testing with high and low $F 1$ onset continua reveal the trading relation, so that ambiguous stimuli in the center of the continuum would be heard as say (stay) when they have a high (low) $F$ l onset, owing to the learned association of say (stay) with a high (low) $F 1$ onset during training?

Such a result would clearly support a perceptuallearning hypothesis, albeit a learning mechanism based on general principles of association, rather than one based 
on specific exposure to a functional language. The next logical question is: Are the trading relations that result from functional linguistic exposure simply based on general principles of association? This would imply that animal models can be developed for human perceptual learning that normally takes place with linguistic exposure.

In fact, it may be necessary to distinguish between several types of trading relations in speech: (1) "spontaneous" trading relations that are based purely on psychoacoustic principles that do not have to be learned (e.g., Kluender \& Lotto, 1994); (2) trading relations that are learned through general principles of association; and (3) trading relations that are learned specifically through linguistic exposure, possibly involving articulatory processes.

Further studies of animal trading relations may help to distinguish between these various possibilities. As was discussed above, our future plans are to expose monkeys to a normal say-stay continuum in which the two cues of gap duration and $F 1$ onset frequency covary normally and then retest them for their sensitivity to the trading relation. The results should be helpful in distinguishing between Hypotheses 2 and 3 above.

\section{REFERENCES}

BEST, C. T. (1995). A direct-realist view of cross-language speech perception. In W. Strange (Ed.), Speech perception and linguistic experience (pp. 171-204). Baltimore: York.

Best, C. T., Morrongiello, B., \& Robson, R. (1981). Perceptual equivalence of acoustic cues in speech and nonspeech perception. Perception \& Psychophysics, 29, 191-211.

Fitch, H. L., Halwes, T., Erickson, D. M., \& Liberman, A. M. (1980). Perceptual equivalence of two acoustic cues for stop-consonant manner. Perception \& Psychophysics, 27, 343-350.

KLUENDER, K. R., \& LOTTO, A. J. (1994). Effects of first formant onset frequency on [-voice] judgments result from auditory processes not specific to humans. Journal of the Acoustical Society of America, 95 , 1044-1052.

KuHL, P. K. (1986). Theoretical contributions of test on animals to the special-mechanisms debate in speech. Experimental Biology, 45, 263-265.

Kuhl, P. K., \& Miller, J. D. (1978). Speech perception by the chinchilla: Identification functions for synthetic VOT stimuli. Journal of the Acoustical Society of America, 63, 905-917.
Lleo, C., \& Prinz, M. (1996). Consonant clusters in child phonology and the directionality of syllable structure assignment. Journal of Child Language, 23, 31-56.

Merriam-Webster's Spanish-English Dictionary (1998). Springfield, MA: Merriam-Webster.

Morrongiello, B. A., Robson, R. C., Best, C. T., \& Ci.ifton, R. K (1984). Trading relations in the perception of speech by 5-yeai-old children. Journal of Experimental Child Psychology, 37, 231-250.

NitTroUer, S. (1992). Age-related differences in perceptual effects of formant transitions within syllables and across syllable boundaries. Journal of Phonetics, 20, 351-382.

OWREN, M. (1990). Acoustic classification of alarm calls by vervet monkeys and humans: 1. Natural calls. Journal of Comparative Psychology, 104, 20-28.

Pisoni, D., Lively, S., \& Logan, S. (1994). Perceptual learning of nonnative speech contrasts: Implications for theories of speech perception. In J. Goodman \& H. Nusbaum (Eds.), The development of speech perception (pp. 121-166). Cambridge, MA: MIT Press.

Simon, C., \& Fourcin, A. (1978). Cross-language study of speechpattern learning. Journal of the Acoustical Society of America, $\mathbf{6 3}$, 925-935.

SinnotT, J. M., \& Brown, C. H. (1997). Perception of the American English liquid /ra-la/ contrast by humans and monkeys. Journal of the Acoustical Society of America, 102, 588-602.

Summerfield, Q., \& HAGGARD, M. (1977). On the dissociation of spectral and temporal cues to the voicing distinction in stop consonants. Journal of the Acoustical Society of America, 62, 435-448.

Underbakke, M., Polka, L., GotTfried, T. L., \& Strange, W. (1988). Trading relations in the perception of $/ \mathrm{r} /-/ 1 /$ by Japanese learners of English. Journal of the Acoustical Society of America, 84, 90-100.

\section{NOTE}

1. It is important to mention some additional unpublished monkey data from Kuhl and Padden (personal communication from Denise Padden to J.M.S. on May 3, 1999). These researchers tested 3 monkeys on the say-stay trading relation, using Best et al.'s (1981) original parameters, and found an average monkey trading relation of $5.4 \mathrm{msec}$. Thus, their data do suggest, in contrast to our own, that a very weak trading relation may exist in monkeys. Nevertheless, they considered their monkey data to be "dissimilar" from both the adult $(19 \mathrm{msec})$ and the child (11 msec) data of Best's group. So, if the Kuhl and Padden data (3 monkeys) are considered together with our own ( 2 monkeys), they indicate an average monkey say-stay trading relation of less than $5 \mathrm{msec}$ at best, which is clearly weaker than any reported in any human population tested so far (see Table 4).

(Manuscript received November 17, 1998; revision accepted for publication August 24, 1999.) 